\title{
Polyclonal light chains in cerebrovascular disease
}

This article was published in the following Dove Press journal:

Neuropsychiatric Disease and Treatment

20 August 2010

Number of times this article has been viewed

\author{
Patrizia Fiori ${ }^{1}$ \\ Maria Giannetti Luigi ${ }^{2}$ \\ Linda lurato' \\ Carminantonio Tammaro ${ }^{3}$ \\ Gigliola Esposito ${ }^{3}$ \\ Antonio Monaco' \\ 'Central Operative Unit of \\ Neurology (Dir. A Monaco), ${ }^{2}$ Infantile \\ Neuropsychiatry and Social Service \\ (Dir. LM Giannetti), ${ }^{3}$ Laboratory \\ (Dir. CA Tammaro), ASL AV, Civil \\ Hospital of Ariano Irpino, University \\ of Naples, Italy
}

Correspondence: Patrizia Fiori Central Operative Unit of Neurology, ASL AV, Civil Hospital of Ariano Irpino, University of Naples, Italy

Tel +39 0825-877354

Fax +39 0825-828409

Email patriziafiorirmit@alice.it

\begin{abstract}
Altered membrane permeability is a hallmark of inflammation and ischemia with systemic spreading. Renal dysfunction is a risk factor for cardiovascular, cerebrovascular, and metabolic diseases. The aim of the present study was to assess proteinuria and urinary polyclonal light chains in acute stroke and chronic cerebrovascular disease compared with other neurologic diseases. Our results showed significantly increased levels of urinary polyclonal light chains in cerebrovascular disease compared with other neurologic diseases. The highest values of urinary polyclonal $\kappa$ chains were found in acute stroke compared with chronic cerebrovascular disease and other neurologic diseases, while the level of $\lambda$ chains was mainly increased in chronic cerebrovascular diseases. The shift to chronic renal failure seems to be signaled by a decreased polyclonal light chain/creatinemia ratio. The absence of a significant correlation with blood pressure and other seric parameters suggests that polyclonal light chains are an early marker of reversible vascular impairment with renal dysfunction before progression to irreversible renal failure and need for dialysis and/or intensive care.
\end{abstract}

Keywords: polyclonal light chains, cerebrovascular disease, renal failure

\section{Introduction}

Altered membrane permeability is a hallmark of inflammation and incipient ischemia, as demonstrated by experimental, radiologic, and pathologic studies. Often, this is a systemic condition, involving retinal, cerebral, cardiac, pulmonary, and renal vessels.

The presence of microalbuminuria is a risk factor both in the general population or in elderly people. ${ }^{1-3}$ Altered kidney function parameters further worsen the clinical course and prognosis of cardiovascular, cerebrovascular, and metabolic diseases. ${ }^{2-11}$ They are associated with white matter lesions, ${ }^{12,13}$ silent brain infarction, ${ }^{14}$ a high prevalence of stroke, ${ }^{15,16}$ worse prognosis, in terms of both short- and long-term morbidity and mortality, ${ }^{9,10}$ and recurrence of vascular events (stroke, myocardial infarction, heart failure). ${ }^{10}$ Pathologic renal findings are also described in young patients affected with stroke, mainly related to hypertensive cardiopathy, nephroangiosclerosis, and chronic pyelonephritis. ${ }^{17}$ Lastly, renal dysfunction is related to cognitive impairment and dementia. ${ }^{18-21}$

Urinary polyclonal light chains are low to middle molecular weight proteins, filtered at the glomerular level and reabsorbed in the tubules by megalin-cubulin receptors. ${ }^{22-25}$ In diabetes, the presence of polyclonal light chains is predictive of nephropathy in the absence of albuminuria. ${ }^{26}$ They herald systemic inflammation and progression of 
renal injury to chronic renal failure. ${ }^{27}$ The aim of the present study was to evaluate proteinuria and urinary polyclonal light chains in acute and chronic cerebrovascular disease.

\section{Materials and methods}

Five-hundred and fifty patients came under our observation from August 2008 to February 2010, 36/553 (0.06\%) of whom bounced back. They were recruited at the Department of Emergency and Assistance or through the Ambulatory Service. They or their family gave informed written consent at admission. The study was approved by the Institutional Review Board. All the patients underwent routine blood and urine examinations, and had an electrocardiogram and computed tomography within 24-48 hours. The diagnoses were acute stroke in 139 (58 males, mean age 75.01, standard deviation $[\mathrm{SD}] \pm 10.85,81$ females, mean age 80.27 \pm 9.04$)$, Glasgow Coma Scale (GCS) $11.67 \pm 2.94$; chronic cerebral vascular disease in 361 (162 males, mean age 73.78 \pm 10.33 , 199 females, mean age 77.61 \pm 8.67$)$, GCS 13.8 \pm 2.03 ; and other neurologic diseases in 50 patients (23 males, mean age $51.79 \pm 4.24,27$ females, mean age $51.72 \pm 20.43)$, GCS $14.56 \pm 1.61$. Seventeen of 139 acute stroke cases $(12 \%)$ were hemorrhagic. Blood pressure values were measured at admission by mercury sphygmomanometer.

\section{Laboratory tests}

Erythrocyte sedimentation rate was performed using standard vials. Serum parameters, ie, natremia, kalemia, glycemia, urea nitrogen, and creatinemia (Cre) were detected by Cobas Integra 800 Analyzer. C-reactive protein was measured by Dade Behring BN ProSpec Nephelometer. Urinary samples were treated with $0.1 \mathrm{M}$ Hepes $0.1 \mathrm{M}$ and $0.2 \mathrm{~g} / \mathrm{L}$ sodium azide, then frozen and stored at $-20^{\circ} \mathrm{C}$. Proteinuria and urinary light chains were analyzed by high-resolution agarose gel electrophoresis on Sebia Hydragel 2 IF and Hydragel 2 Bence Jones immunofixation with anti-light chain antibodies and detection by a semiautomatic Hydrasis system. Some samples were analyzed by nephelometric immunoassay with specific anti-free light chain antibodies. The assay sensitivity was $<1 \mathrm{mg} / \mathrm{L}$. Normal ranges for the studied parameters are reported in Table 1. Urinary tract infection and Bence Jones-positive samples were excluded from the statistical analysis.

\section{Statistical analysis}

This was performed using the unpaired t-test, for standard description of baseline characteristics and differences among the study groups, and by Pearson correlation test and logarithmic regression analysis for identification of

Table I Normal ranges for the studied parameters

\begin{tabular}{|c|c|c|c|c|c|c|c|}
\hline & \multirow[t]{2}{*}{ Normal values } & \multirow[t]{2}{*}{ OND } & \multirow[t]{2}{*}{ CCVD } & \multirow[t]{2}{*}{ AS } & \multicolumn{3}{|l|}{$T$ test } \\
\hline & & & & & AS vs OND & AS vs CVD & CCVD vs OND \\
\hline Age (years) & & $51.11 \pm 19.22$ & $75.90 \pm 9.61$ & $78.52 \pm 10.04$ & ns & ns & ns \\
\hline GCS & 15 & $14.56 \pm 1.61$ & $13.8 \pm 2.03$ & $11.67 \pm 2.94$ & ns & ns & ns \\
\hline SBP & $120-129 \mathrm{mmHg}$ & $122.11 \pm 16.66$ & $137.13 \pm 20.57$ & $|42.45 \pm 23.7|$ & ns & ns & ns \\
\hline DBP & $80-84 \mathrm{mmHg}$ & $78.17 \pm 11.54$ & $80.08 \pm 11.18$ & $82.17 \pm 12.53$ & $P 0.05$ & ns & ns \\
\hline MAP & $93-96 \mathrm{mmHg}$ & $92.78 \pm 12.15$ & $99.12 \pm 12.76$ & $102.18 \pm 14.7$ & ns & ns & $P 0.002$ \\
\hline $\mathrm{Na}$ & |36-145 mEq/L & $138 \pm 4.09$ & $\mid 36.84 \pm 4.87$ & $137.5 \pm 3.23$ & ns & ns & ns \\
\hline K & $3.30-5.1 \mathrm{mEq} / \mathrm{L}$ & $4.08 \pm 0.45$ & $4.14 \pm 0.67$ & $4.06 \pm 0.57$ & ns & ns & ns \\
\hline Gly & $70-110 \mathrm{mg} / \mathrm{dL}$ & $90.42 \pm 18.40$ & $101.34 \pm 36$ & $111.25 \pm 38.49$ & $P 0.001$ & ns & ns \\
\hline UN & $10-50 \mathrm{mg} / \mathrm{dL}$ & $41.79 \pm 23.54$ & $48.55 \pm 23.69$ & $48.38 \pm 24.08$ & $P 0.03$ & ns & ns \\
\hline Cre & $\begin{array}{l}\text { (males } 0.7-1.2 \text {, } \\
\text { females } 0.5-0.9 \text { ) } \mathrm{mg} / \mathrm{dL}\end{array}$ & $0.83 \pm 0.36$ & $0.95 \pm 0.45$ & $0.95 \pm 0.77$ & ns & ns & ns \\
\hline ESR & $0-2$ & $11.15 \pm 12.16$ & $20.85 \pm|8.7|$ & $20 \pm 26.9$ & $P 0.005$ & ns & $P 0.004$ \\
\hline CRP & $0-5 \mathrm{mg} / \mathrm{L}$ & $11.35 \pm 28.01$ & $20.17 \pm 12.16$ & $19.62 \pm 31.88$ & ns & ns & ns \\
\hline UD & $1005-1030$ & $1017 \pm 7.6$ & $1015 \pm 6.21$ & $1018 \pm 7.24$ & ns & $P 0.006$ & $P 0.01$ \\
\hline Proteinuria & 0 & $17.81 \pm 37.17$ & $21.49 \pm 44.31$ & $19.62 \pm 31.88$ & ns & ns & ns \\
\hline Urinary $\kappa$ chains & $0-7.1 \mathrm{mg} / \mathrm{L}$ & $11.34 \pm 12.44$ & $21.65 \pm 29.41$ & $24.16 \pm 26$ & $P 0.001$ & ns & $P 0.01$ \\
\hline Urinary $\lambda$ chains & $0-3.9 \mathrm{mg} / \mathrm{L}$ & $4.98 \pm 4.27$ & $11.97 \pm 51.70$ & $9.04 \pm 9.19$ & $P 0.004$ & ns & $P 0.02$ \\
\hline PLC ratio & $\mathrm{I}-5$ & $2.15 \pm 0.74$ & $2.47 \pm 1.26$ & $2.62 \pm 1$ & $P 0.056$ & ns & ns \\
\hline$\kappa /$ Cre ratio & $0-5.9$ & $0.17 \pm 0.11$ & $0.09 \pm 0.02$ & $0.42 \pm 0.47$ & $P 0.001$ & ns & $P 0.02$ \\
\hline$\lambda /$ Cre ratio & $0-3.25$ & $0.06 \pm 0.01$ & $0.05 \pm 0.02$ & $0.12 \pm 0.10$ & $P 0.01$ & ns & $P 0.04$ \\
\hline
\end{tabular}

Abbreviations: AS, acute stroke; CCVD, chronic cerebrovascular disease; Cre, creatinemia; ESR, erythrocyte sedimentation rate; CRP, C-reactive protein; GCS, Glasgow Coma Scale; Gly, glycemia; K, kalemia; N, natremia; OND, other neurological diseases; PLC, polyclonal light chains; SD standard deviation; UD urinary density; UN, urea nitrogen; DBP, diastolic blood pressure; SBP, systolic blood pressure; MAP, mean arterial pressure. 
association between the study parameters. $P$ values $<0.05$ were considered significant.

\section{Results}

Our data showed proteinuria in 116/149 (78\%) acute stroke patients $(26.85 \pm 42.39 \mathrm{mg} / \mathrm{dL}), 265 / 384(69 \%)$ chronic cerebrovascular disease patients $(21.49 \pm 40.74 \mathrm{mg} / \mathrm{dL})$, and $35 / 53(66 \%)$ patients with other neurologic diseases $(17.81 \pm 37.17 \mathrm{mg} / \mathrm{dL}$, see Table 1$)$. No statistically significant difference was found between proteinuria in acute stroke, chronic cerebrovascular disease, and other neurologic diseases. Urinary polyclonal light chains were mainly detected in cerebrovascular patients, with the highest significant levels of $\kappa$ chains in acute stroke $(24.16 \pm 26 \mathrm{mg} / \mathrm{L})$ compared with chronic cerebrovascular disease $(21.65 \pm 29.41 \mathrm{mg} / \mathrm{L})$ and other neurologic diseases $(11.34 \pm 12.44 \mathrm{mg} / \mathrm{L}$; acute stroke versus other neurologic diseases, $P 0.001$, and chronic cerebrovascular disease versus other neurologic diseases, $P 0.01$. The level of $\lambda$ chains was $9.04 \pm 9.19 \mathrm{mg} / \mathrm{L}$ in acute stroke, $11.97 \pm 51.70 \mathrm{mg} / \mathrm{L}$ in chronic cerebrovascular disease, and $4.98 \pm 4.27 \mathrm{mg} / \mathrm{L}$ in other neurologic diseases (acute stroke versus other neurologic diseases, $P 0.004$ and chronic cerebrovascular disease versus other neurologic diseases, $P 0.02$, Figure 1). A trend towards a difference in the urinary polyclonal light chain ratio was found between acute stroke and other neurologic diseases (acute stroke $2.62 \pm 1.0$, other neurologic diseases $2.15 \pm 0.74, P 0.05$ ). The polyclonal light chain/Cre ratio was increased in acute stroke (acute stroke $\kappa /$ Cre $0.42 \pm 0.47$; acute stroke $\lambda /$ Cre $0.12 \pm 0.10$ ), but was relatively decreased in chronic cerebrovascular disease (chronic cerebrovascular disease $\kappa / C r e ~ 0.09 \pm 0.02$; chronic cerebrovascular disease $\lambda /$ Cre $0.05 \pm 0.02$ ) compared with acute stroke and other neurologic diseases (other neurologic diseases $\kappa /$ Cre $0.17 \pm 0.11$; other neurologic diseases $\lambda /$ Cre $0.06 \pm 0.01$; and acute stroke $\kappa /$ Cre versus other neurologic diseases $\kappa / \mathrm{Cre}, P 0.001$; acute stroke $\kappa / \mathrm{Cre}$ versus chronic cerebrovascular disease $\kappa /$ Cre, not statistically significant; chronic cerebrovascular disease $\kappa / C$ re ratio versus other neurologic diseases $\kappa / \mathrm{Cre}, P 0.02$; acute stroke $\lambda / \mathrm{Cre}$ versus other neurologic diseases $\lambda / \mathrm{Cre}, P 0.01$; acute stroke $\lambda /$ Cre versus chronic cerebrovascular disease $\lambda /$ Cre, not statistically significant; chronic cerebrovascular disease $\lambda / \mathrm{Cre}$ versus other neurologic diseases $\lambda / \mathrm{Cre}, P 0.04$, Figure 2$)$. At case history, hypertension was referred by $127 / 149$ (85.23\%) of acute stroke patients, 293/384 (76.3\%) of patients with chronic cerebrovascular disease, 18/53 (34\%) patients with other neurologic diseases, and diabetes was present in 29/149 (19.46\%) patients with acute stroke, 65/384 (16.92\%) with chronic cerebrovascular disease, and 1/53 (0.01\%) with other neurologic diseases. No significant correlation was found

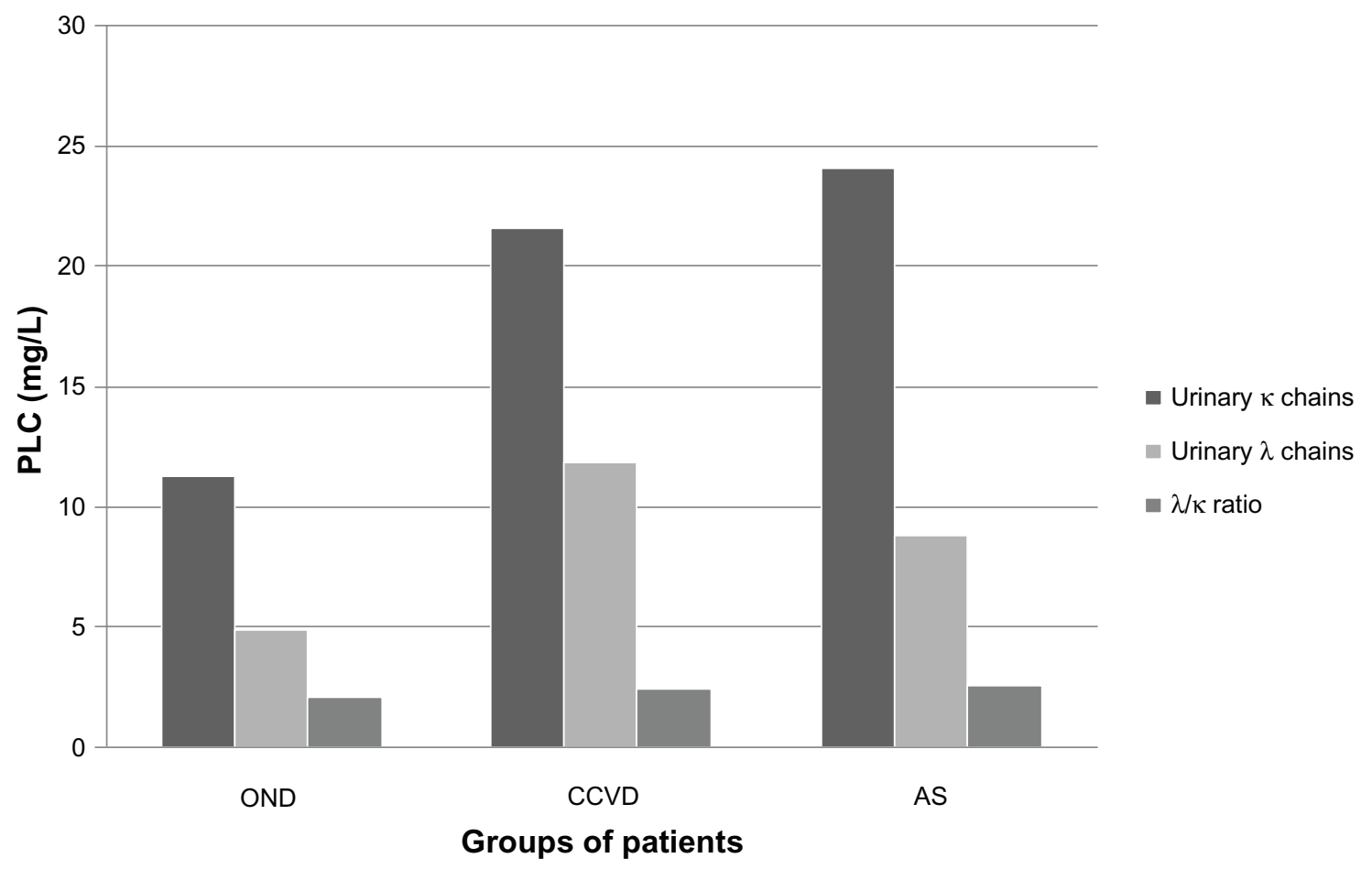

Figure I Urinary PLCs In cerebrovascular dieseas (AS, CCVD) compared to OND.

Abbreviations: PLCs, polyclonal light chains; OND, other neurological disease; AS, acute stroke; CCVD, chronic cardiovascular disease. 


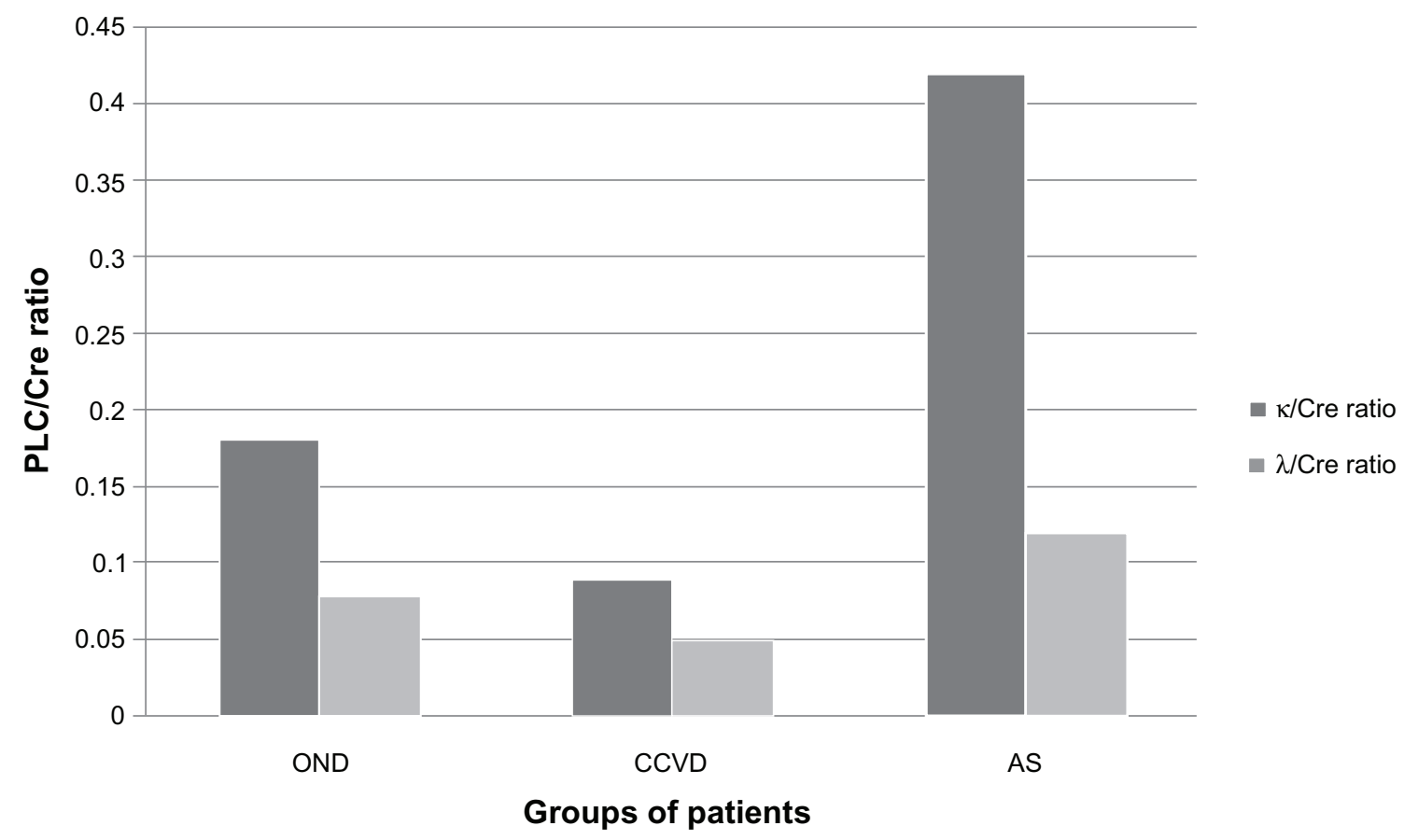

Figure 2 Urinary PLCs/Cre ratio in cerebrovascular dieseas (AS, CCVD) compared to OND.

Abbreviations: PLCs, polyclonal light chains; OND, other neurological disease; AS, acute stroke; CCVD, chronic cardiovascular disease; Cre, creatinemia.

for proteinuria, urinary polyclonal light chains, systolic, diastolic, and mean arterial pressure values, and natremia, kalemia, glycemia, urea nitrogen, and creatinemia.

\section{Conclusion}

Our finding of a significant increase in urinary polyclonal light chains in acute and chronic vascular patients compared with those having other neurologic diseases, in the absence of a significant correlation with other systemic and renal parameters, suggests that urinary polyclonal light chains represent an early systemic marker of altered membrane permeability. The higher and more significant level of $\kappa$ compared with $\lambda$ chains in acute stroke can be explained by their higher physiologic production, up to twice the rate of $\lambda .^{22}$ Their further increase in pathologic conditions is counterbalanced by augmented elimination and reduced reabsorption at the tubular level. $\Lambda$ chains more frequently form dimers that slow their renal clearance. We observed a relatively insignificant increase in urinary $\lambda$ chains in chronic cerebrovascular disease compared with acute stroke. In tubular proteinuria, an increase of urinary low molecular weight proteins, as $\lambda$ dimers, was detected. This is attributed to an increased excretion, a failure of proximal tubule reabsorption, and reduced catabolism. ${ }^{23}$ Unfolding intermediates are found after exposure to denaturing conditions, such as urea, heat, and $\mathrm{pH}$ variation. ${ }^{25}$ Higher seric concentrations of polyclonal light chains and a higher urinary polyclonal light chain/Cre ratio, together with increased glomerular filtration and reduced reabsorption at the tubular level have been reported. ${ }^{24,27}$ Serum and urinary concentrations of polyclonal light chains are related to the severity and progression of renal dysfunction. ${ }^{27}$ Taken together, our data suggest that the increase in urinary polyclonal light chains may be a negative prognostic sign and represent the boundary between a reversible stage of renal dysfunction, namely nephrotic syndrome, in which there is still an opportunity for therapeutic intervention, and a definite progression to chronic kidney disease, indicated by a decreased polyclonal light chain/Cre ratio. This precedes an irreversible cascade of events characterized by reduction of glomerular filtration, ${ }^{27}$ systemic interstitial and parenchymal edema, infection, tubular necrosis, progression to uremia and irreversible renal failure, and need for emergency treatment, such as ventilatory assistance and hemodialysis. Therefore, it is important to prevent systemic complications that threaten the lives of patients, prolong hospitalization, cause frequent bounce-backs, diminish quality of life, and add further costs for sanitary assistance. The sensibility and specificity of such an assay for urinary polyclonal free light chains, their predictive role concerning short- and long-term prognosis, and the association with cardiac and renal echographic and magnetic resonance imaging parameters are under evaluation. 


\section{Disclosure}

The authors report no conflict of interest in this work.

\section{References}

1. Damsgaard EM, Froland A, Jorgensen OD, Mogensen CE. Microalbuminuria as predictor of increased mortality in elderly people. BMJ. 1990;300:297-300.

2. Hillege HL, Fidler V, Diercks GF, et al; Prevention of Renal and Vascular End Stage Disease (PREVEND) Study Group: Urinary albumin excretion predicts cardiovascular and non cardiovascular mortality in the general population. Circulation. 2002;106:1777-1782.

3. Klausen K, Borch-Johnsen K, Fedt-Rasmussen B, et al. Very low levels of microalbuminuria are associated with increased risk of coronary heart disease and death independently of renal function, hypertension and diabetes. Circulation. 2004;110:32-35.

4. Barzilay JI, Peterson D, Cushman M, et al. The relationship of cardiovascular risk factors to microalbuminuria in older adults with or without diabetes mellitus or hypertension: The Cardiovascular Health Study. Am J Kidney Dis. 2004;44:25-34.

5. Seliger SL, Gillen DL, Longstreth WT, Kestenbaum B, Stehman-Breen CO. Elevated risk of stroke among patients with endstage disease. Kidney Int. 2003;64:603-609.

6. Diercks GF, van Boven AJ, Hillege HL, et al. Microalbuminuria is independently associated with ischaemic electrocardiographic abnormalities in a large non-diabetic population. The PREVEND (Prevention of REnal and Vascular ENdstage Disease) study. Eur Heart J. 2000;21:1922-1927.

7. Gerstein HC, Mann JF, Yi Q, et al. Albuminuria and risk of cardiovascular events, death and heart failure in diabetic and nondiabetic individuals. JAMA. 2001;286:421-426.

8. Jassal SK, Langenberg C, von Muhlen D, Bergstrom J, Barrett-Connor E. Usefulness of microalbuminuria vs the metabolic syndrome as a predictor of cardiovascular disease in women and men $>40$ years of age (from the Rancho Bernardo Study). Am J Cardiol. 2008;101:1275-1280.

9. Mostofky E, Wellenius GA, Noheria A, et al. Renal function predicts survival in patients with acute ischemic stroke. Cerebrovasc Dis. 2009;28:88-94.

10. Tsagalis G, Akrivos T, Alevizaki M, et al. Long-term prognosis of acute kidney injury after first acute stroke. Clin J Am Soc Nephrol. 2009;4:616-622.

11. Wachtell K, Ibsen $\mathrm{H}$, Olsen $\mathrm{MH}$, et al. Albuminuria and cardiovascular risk in hypertensive patients with left ventricular hypertrophy: The LIFE study. Ann Intern Med. 2003;139:901-906.

12. Khatri M, Wright CB, Nickolas TL, et al. Chronic kidney diasease is associated with white matter hyperintensity volume. The Northern Manhattan Study. Stroke. 2007;38:3121-3126.

13. Weiner DA, Bartolomei K, Scott T, et al. Albuminuria, cognitive functioning and white matter hyperintensities in homebound elders. Am J Kidney Dis. 2009;53:438-447.
14. Kobayashi M, Hirawa N, Yatsu K, et al. Relationship between silent brain infarction and chronic kidney disease. Nephrol Dial Transplant. 2009;24:201-207.

15. Wannamethee SG, Shaper AG, Perry IJ. Serum creatine concentration and risk of cardiovascular disease: A possible marker for increased risk of stroke. Stroke. 1997;28:557-563.

16. Abramson JL, Jurkovitz CT, Vaccarino V, Weintraub WS, McClellan W. Chronic kidney disease, anemia and incident stroke in a middle-aged, community-based population: The ARIC study. Kidney Int. 2003;64:610-615.

17. Arismendi-Morillo G, Fernandez-Abreu M, Cardozo-Duran J, VilchezBarrios G. Importance and repercussions of renal and cardiovascular pathology on stroke in young adults: An anatomopathologic study of 52 clinical necropsies. Clinics. 2008;63:15-20.

18. Seliger SL, Siscovick DS, Stehman-Breen CO, et al. Moderate renal impairment and risk of dementia among older adults: The Cardiovascular Health Cognition Study. J Am Soc Nephrol. 2004;15:1904-1911.

19. Kurella-Tamura M, Wadley V, Yaffe K, et al. Kidney function and cognitive impairment in US adults: The REGARDS (Reasons for Geographic and Racial Differences in Stroke) Study. Am J Kidney Dis. 2008;52:227-234

20. Kurella M, Yaffe K, Shlipak MG, Wenger NK, Chertow GM. Chronic kidney disease and cognitive impairment in menopausal women. $\mathrm{Am}$ J Kidney Dis. 2005;45:66-76.

21. Barzilay JI, Fitzpatrick AL, Luchsinger J, et al. Albuminuria and dementia in the elderly: A community study. Am J Kidney Dis. 2008;52:216-226.

22. Nezlin R. Human immunoglobulins. In: Nezlin R, Roald S, editors. The Immunoglobulins: Structure and Function. New York: Academic Press; 1998.

23. Klassen RB, Allen PL, Batuman V, Crenshaw K, Hammond TG. Light chains are a ligand for megalin. J Appl Physiol. 2005;98:257-263.

24. Waldmann TA, Strober W, Mogielnicki RP. The renal handling of low molecular weight proteins. II. Disorders of serum protein catabolism in patients with tubular proteinuria, the nephrotic syndrome, or uremia. J Clin Invest. 1972;51:2162-2174.

25. Chung CM, Chiu JD, Connors LH, et al . Thermodynamic stability of a kappal immunoglobulin light chain: Relevance to multiple myeloma. Biophys J. 2005;88:4232-4242.

26. Groop L, Stenman S, Groop PH, Makipernaa A, Teppo AM. The effect of exercise on urinary excretion of different size proteins in patients with insulin-dependent diabetes mellitus. Scand J Clin Lab Invest. 1990;50:525-532.

27. Hutchinson CA, Harding S, Hewins P, et al. Quantitative assessment of serum and urinary polyclonal free light chains in patients with chronic kidney disease. Clin J Am Soc Nephrol. 2008;3:1684-1690.
Neuropsychiatric Disease and Treatment

\section{Publish your work in this journal}

Neuropsychiatric Disease and Treatment is an international, peerreviewed journal of clinical therapeutics and pharmacology focusing on concise rapid reporting of clinical or pre-clinical studies on a range of neuropsychiatric and neurological disorders. This journal is indexed on PubMed Central, the 'PsycINFO' database and CAS, and is the official

\section{Dovepress}

journal of The International Neuropsychiatric Association (INA). The manuscript management system is completely online and includes a very quick and fair peer-review system, which is all easy to use. Visit http://www.dovepress.com/testimonials.php to read real quotes from published authors. 